\title{
Effect of alkali/mixed alkali metal ions on the thermal and spectral characteristics of $\mathrm{Dy}^{3+}: \mathrm{B}_{2} \mathrm{O}_{3}-\mathrm{PbO}-\mathrm{Al}_{2} \mathrm{O}_{3}-\mathrm{ZnO}$ glasses
}

\begin{abstract}
Thermal and spectroscopic features of $50 \mathrm{~B}_{2} \mathrm{O}_{3}-10 \mathrm{PbO}-10 \mathrm{Al}_{2} \mathrm{O}_{3}-10 \mathrm{ZnO}-(\mathrm{x}) \mathrm{Li}_{2} \mathrm{O}-(\mathrm{y})$ $\mathrm{Na}_{2} \mathrm{O}-(\mathrm{z}) \mathrm{K}_{2} \mathrm{O}-1.0 \mathrm{Dy}_{2} \mathrm{O}_{3}(\mathrm{~mol} \%)(\mathrm{x}=19, \mathrm{y}=0$, and $\mathrm{z}=0 ; \mathrm{x}=0, \mathrm{y}=19$, and $\mathrm{z}=0 ; \mathrm{x}=0$, $\mathrm{y}=0$, and $\mathrm{z}=19 ; \mathrm{x}=9.5, \mathrm{y}=9.5$, and $\mathrm{z}=0 ; \mathrm{x}=9.5, \mathrm{y}=0$, and $\mathrm{z}=9.5 ; \mathrm{x}=0, \mathrm{y}=9.5$, and $\mathrm{z}=9.5)$ glasses, that were fabricated by utilizing melt-quenching approach, are investigated by thermogravimetric analysis (TGA), differential scanning calorimetry (DSC), optical absorption, photoluminescence excitation (PLE), photoluminescence (PL), and PL decay lifetimes. PL spectra for all the $\mathrm{Dy}^{3+}$-doped samples show emission bands at $453 \mathrm{~nm}$ (blue), $482 \mathrm{~nm}$ (blue), $573 \mathrm{~nm}$ (yellow), $662 \mathrm{~nm}$ (red), and $752 \mathrm{~nm}$ (red) corresponding to the ${ }^{4} \mathrm{I}_{15 / 2} \rightarrow{ }^{6} \mathrm{H}_{15 / 2},{ }^{4} \mathrm{~F}_{9 / 2} \rightarrow{ }^{6} \mathrm{H}_{15 / 2},{ }^{4} \mathrm{~F}_{9 / 2} \rightarrow{ }^{6} \mathrm{H}_{13 / 2},{ }^{4} \mathrm{~F}_{9 / 2} \rightarrow{ }^{6} \mathrm{H}_{11 / 2}$, and ${ }^{4} \mathrm{~F}_{9 / 2} \rightarrow{ }^{6} \mathrm{H}_{9 / 2}$ transitions, respectively, upon excitation at $350 \mathrm{~nm}$. Here, $\mathrm{Dy}^{3+}: \mathrm{Li}-\mathrm{Na}$ glass shows the highest PL intensity for all identified emissions. The yellow-to-blue (Y/B) emission intensity ratio (varied within the range 1.257-1.376), CIE chromaticity coordinates (x,y) (slight variation between $(0.3410,0.3802)$ and $(0.3495,0.3872)$, and correlated color temperatures (CCTs) (changed from $4953 \mathrm{~K}$ to $5212 \mathrm{~K}$ ) are calculated following the PL spectra. Dy ${ }^{3+}:{ }^{4} \mathrm{~F}_{9 / 2}$ decay curves show non-exponential behavior and are fitted by the Inokuti-Hirayama (I-H) model, where $S=6$ shows best fit, indicating dipole-dipole (d-d) interactions for $\mathrm{Dy}^{3+}$ excited (donor) and ground state (acceptor) ions.
\end{abstract}

Keyword: $\mathrm{Dy}^{3+}: \mathrm{B}_{2} \mathrm{O}_{3}-\mathrm{PbO}-\mathrm{Al}_{2} \mathrm{O}_{3}-\mathrm{ZnO}$ glass; TGA/DSC; Judd-Ofelt theory; Luminescence property; Decay lifetime; Inokuti-Hirayama (I-H) model 